\title{
BIOREPORTER BACTERIA FOR LANDMINE DETECTION
}

Robert S. Burlage ${ }^{1^{*}}$, Tanya Youngblood ${ }^{2}$, and Douglas Lamothe ${ }^{3}$

$$
\text { CONF- } 980425-
$$

1. Environmental Sciences Division

Oak Ridge National Laboratory

Oak Ridge TN 37831-6036

tel: $423-574-7321$

fax: 423-576-8543

e-mail: RVX@ORNL.GOV

2. Frisby Technologies

3635 Whiskey Road

Aiken, SC 29803

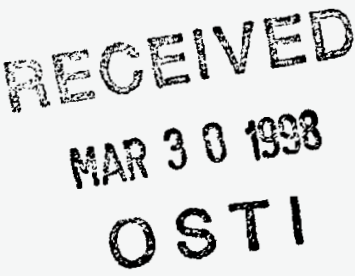

3. Ordnance/Explosives Environmental

Services Division,

American Technologies, Inc.

Huntsville, AL 35816

* to whom correspondence should be addressed

"The submitted manuseript has been authored by a contractor of the U.S. government under contract no. DE-AC05-960R22464 Accordingly, the U.S. government retains a nonexclusive, royalty-free license to publish or reproduce the published form of this contribution, or allow others to do so, for U.S. Govemment purposes."

DISTRIBUTION OF THIS DOCUMENT IS UNLIMTTEO

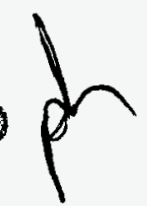




\section{DISCLAIMER}

This report was prepared as an account of work sponsored by an agency of the United States Government. Neither the United States Government nor any agency thereof, nor any of their employees, makes any warranty, express or implied, or assumes any legal liability or responsibility for the accuracy, completeness, or usefulness of any information, apparatus, product, or process disclosed, or represents that its use would not infringe privately owned rights. Reference herein to any specific commercial product, process, or service by trade name, trademark, manufacturer, or otherwise does not necessarily constitute or imply its endorsement, recommendation, or favoring by the United States Government or any agency thereof. The views and opinions of authors expressed herein do not necessarily state or reflect those of the United States Government or-any agency thereof. 


\begin{abstract}
Landmines (and other UXO) gradually leak explosive chemicals into the soil at significant concentrations. Bacteria, which have adapted to scavenge low concentrations of nutrients, can detect these explosive chemicals. Uptake of these chemicals results in the triggering of specific bacterial genes. We have created genetically recombinant bioreporter bacteria that detect small concentrations of energetic chemicals. These bacteria are genetically engineered to produce a bioluminescent signal when they contact specific explosives. A gene for a brightly fluorescent compound can be substituted for increased sensitivity. By finding the fluorescent bacteria, you find the landmine. Detection might be accomplished using stand-off illumination of the minefield and GPS technology, which would result in greatly reduced risk to the deminers. Bioreporter technology has been proven at the laboratory scale, and will be tested under field conditions in the near future.

We have created a bacterial strain that detects sub-micromolar concentrations of $o$ and $p$-nitrotoluene. Related bacterial strains were produced using standard laboratory protocols, and bioreporters of dinitrotoluene and trinitrotoluene were produced, screening for activity with the explosive compounds. Response time is dependent on the growth rate of the bacteria. Although full signal production may require several hours, the bacteria can be applied over vast areas and scanned quickly, producing an equivalent detection speed that is very fast. This technology may be applicable to other needs, such as locating buried explosives at military and ordnance/explosive manufacturing facilities.
\end{abstract}

\title{
Introduction
}




\section{Introduction}

Old mine fields remain active, endangering non-combatants long after the war is over. Identifying the location of these mines is a difficult and dangerous occupation. The mines have few properties that make them stand out from the soil in which they are placed. However, old landmines (and other UXO) gradually leak small concentrations of their explosives into the soil. Vapors from these explosives have been detected by dogs; concentrations in the soil are probably significantly higher (ppm - ppb).

Explosive chemicals can be detected by bacteria, which have adapted to scavenge low concentrations of nutrients (Figure 1). Uptake of these chemicals results in the triggering of specific genes in the bacteria. We have created bioreporter bacteria that detect the location of leaking mines by scavenging the small amounts of explosives around a mine. These bacteria are genetically engineered to produce a noticeable signal (bioluminescence or fluorescence) in response to the presence of specific explosives. By finding the glowing bacteria, you find the landmine.

We have experience in working with these types of bioreporter bacteria through our work with hazardous wastes. We have published work on bacterial strains for detection of hydrocarbons (e.g., toluene, naphthalene) $(1,4)$, mercury (both organic and inorganic) (6), and a variety of exotic bioreporters of environmental conditions (e.g. nutrient starvation, DNA damaging events). These strains are based on a bioluminescent bioreporter, and are extremely sensitive (3). For instance, published results for mercury show detectability at a sub-nanomolar concentration, while detectable concentrations of naphthalene in the part-per-million range are routine. We will be able to increase our 
sensitivity using the new fluorescent bioreporter, which is easier to detect and creates a stable signal.

We will field test this technology in late 1998 on a quarter acre-sized plot that has been amended with landmines and UXO. Preparations for this test and the identification of the microorganisms that will be used are described in this report.

\section{Methods}

This work is dependent on the creation of a bacterial strain that responds to the presence of an explosive chemical. We have selected trinitrotoluene as the explosive of interest, and Pseudomonas putida as the microorganism. This strain was selected because it already possessed a set of genes that respond to chemicals that are related to explosives of interest. When these genes become induced after contact with an explosive chemical, they produce a bioluminescent response. That is, they emit visible light that can be easily and sensitively detected using conventional photodetectors. A chemical mutagenesis procedure was used to create the DNT and TNT strains (2). The mutant bacterial colonies were screened by spraying them with the explosive compound in a solution of dimethylformamide, and then exposing them to photographic film. Colonies that produce light in response to the explosive are detectable as spots on the film after it is developed. We have picked several of these colonies for further characterization, including sequence analysis of the DNA of interest. We have found that the mutations fall into three categories: (1) those that are responsive to DNT but not TNT, (2) those that are responsive to TNT but not DNT, and (3) those that respond to both DNT and TNT. 
Representative examples of each class are presently being analyzed for the gene sequence, and we anticipate that the results will demonstrate which area of the gene is vital for interaction with the explosive chemical.

\section{Results and Discussion:}

The central feature of this proposal is the creation of a genetically recombinant bacterial strain that scavenges specific explosive chemicals, and which then responds by producing large amounts of a bioluminescent or fluorescent signal. Bacteria which degrade explosives have been studied extensively, and genetic techniques to modify the strains are available. The expression of these degradation genes is controlled by a regulatory protein that also recognizes the explosive chemical; only in the presence of the chemical will the regulatory protein activate the degradation genes.

The DNT and TNT bioreporter strains that we describe here utilize the lux genes, which allow the microorganism to become bioluminescent. A typical response curve of a bioreporter strain is shown in Figure 2. This strain was grown in the laboratory in a rich medium, and then the medium was amended with o-nitrotoluene at a final concentration of 1 micromolar. Over a period of hours the light production from the induced strain increases markedly (broken line) while the light production from the uninduced control (solid line) is negligible. The response is slow in this case because the amendment was performed during the fast (exponential) growth of the strain. It has been shown in other studies that polar compounds that resemble toluene do not induce the catabolic genes until the growth rate of the culture slows i.e. until the cells enter a stationary phase of growth. 
Our results here are in full agreement with these prior results. A faster response from the strain can thus be achieved by growing the cells to stationary phase and then introducing the explosive. Under these conditions light production can easily be detected within the first 30 minutes after addition.

A genetic fusion between a fluorescence bioreporter gene and the explosiveresponsive gene must be created next. The gene for Green Fluorescent Protein (GFP) will be used because it results in a protein of extremely bright fluorescence. This fusion can be produced using a special vector developed in this laboratory (5). A benefit of using this special vector is that an induced gene will remain permanently induced, allowing production of large amounts of GFP. Overproduction of GFP will make the cells easier to detect.

We will test the bioluminescent and fluorescent bioreporter strains on a realistic minefield during the latter part of 1998. A site in South Carolina has been selected, and this site will be modified with a variety of landmines and possibly other UXO as well. The site will determine the means of application of the bacterial culture, since small test plots could be covered using a hand sprayer. The bacteria typically survive well with this type of treatment. Conditions for application and detection would mimic those used under actual field conditions. The main question to be answered in this experiment is whether the mines are leaking an amount of explosives that is sufficient to trigger the bacterial response.

We will test our technology according to the plan shown in Figure 3. The bacteria will be grown in large fermentors located at a nearby college. Approximately 100 gallons of bacterial culture will be grown. This culture will be sprayed evenly over the surface of 
the minefield using conventional equipment; in this case a large farm sprayer will probably be used, although a cropduster might be used for larger areas. A passage of approximately three hours is required for the bacteria to contact the explosive chemicals, react to them and produce the bioreporter (shown here as the fluorescent bioreporter). The detection phase requires exposure to an ultraviolet light, which can be as simple as a handheld device or as complex as a vehicle-mounted detector. It is possible that conventional military equipment might be easily adapted for detection of the fluorescent hotspots, although the UV lamp and detection apparatus represent off-the-shelf technology, and are not expensive.

If the field demonstration is successful then conventional application becomes an immediate possibility. We believe that the unique attributes of this technology make it very attractive for humanitarian demining, particularly for countries that can not accommodate high budgets or high technological demands. The cost for this technology is very low: the bacteria can be cultured for a few dollars per gallon and applied using conventional spray techniques. It is noteworthy that this task is accomplished without undue risk to the personnel involved i.e. entry into the minefield area is not required. The detection equipment can get sophisticated, but can be as simple and affordable as a handheld UV light. More sophisticated detectors may be able to perform their task in the daylight, by shielding the area under examination from daylight. Increased fluorescent detector sensitivity would result in more mines detected, particularly those mines that are leaking only trace amounts of explosives. In each case the technology requires little or no 
development, is inexpensive and easy to operate. However, for the proof-of-principle experiment only the conventional UV light and technician will be used.

The detector in this technique is the bacterial strain, which can be carried virtually anywhere and grown to field-scale volumes using common microbiological practices. The bacteria must contact the explosives in the soil in order for a response to be generated. Conditions that prevent soil contact (ice, snow, very heavy vegetation) should be avoided. A downpour of rain would tend to wash the bacteria away, although a light drizzle would probably not be an obstacle, and might even improve detection. Application and detection equipment, as described above, represent off-the-shelf technology and are neither expensive nor cumbersome, and are easy to operate.

One of the great strengths of this technology is that the sensing phase of the work allows the operator to find the landmine very quickly, literally as fast as his eyes can scan the ground. Photoelectric means of detection will undoubtedly make this step go even faster. Because of the way that the bacteria are prepared, it is in the best interest of the users to examine large areas rather than small, since the preparation phase is slow (the rate-limiting step) and the sensing phase is very rapid.

This technique should be applicable to discovery of all types of explosives and UXO in the soil. Different types of explosives (e.g. TNT and RDX) can be detected using a "cocktail" of different bioreporter bacteria. This technology should also be applicable to detection of propellants from projectiles, and therefore can be used to clear old firing ranges. 


\section{Acknowledgments}

Research sponsored by the Defense Special Weapons Agency, and by the SBIR Program, U.S. Department of Defense. Oak Ridge National Laboratory is managed by Lockheed Martin Energy Research Corp. for the U.S. Department of Energy under contract number DE-AC05-960R22464.

\section{References}

1. Burlage, R.S. Emerging technologies: bioreporters, biosensors, microprobes, in "Manual Of Environmental Microbiology", ASM Press, Washington, D.C. 1996.

2. Burlage, R.S., R. Atlas, R. Colwell, G. Geesey, G.Sayler, and D. Stahl, (editors) "Techniques in Microbial Ecology", Oxford University Press, New York. 1997.

3. Burlage, R.S. and C.T. Kuo. 1994. Living biosensors for management and manipulation of microbial consortia, Annual Review of Microbiology 48: 291-309.

4. Burlage, R.S., A.V. Palumbo, A. Heitzer, and G.S. Sayler. 1993. Bioluminescent reporter bacteria detect contaminants in soil samples. Appl. Biochem. Biotech. 45/46: 731-740.

5. Burlage, R.S., Z. Yang, and T. Mehlhorn. 1995. A transposon for green fluorescent protein transcriptional fusions: application for bacterial transport experiments. Gene 173: 53-58.

6. Selifonova, O., R. Burlage, and T. Barkay. 1993. Preparation of bioluminescent sensors for detection of $\mathrm{Hg}$ (II) in the environment. Appl. Environ. Microbiol. 59: 30833090.

\section{Figure Legends}

Figure 1. This is a cartoon of a single microbial cell in a soil environment. The cell

contacts particles of explosives, which are taken up by the cell and there trigger a gene. A gene fusion with the GFP gene allows the cell to become fluorescent.

Figure 2. The response curve of a microbial strain to o-nitrotoluene. The chemical was supplied at a final concentration of 1 micromolar, and light measurements were recorded 
using an ATP photometer. Relative Light Units (RLU) are used to compare light output from the induced (broken line) and uninduced (solid line) strains. Note that several hours are needed for the full effect to be apparent.

Figure 3. A schematic of the steps needed for field deployment of this technology. Fields ranging from garden plot size to many hundreds of acres can be examined using the same basic technology. 


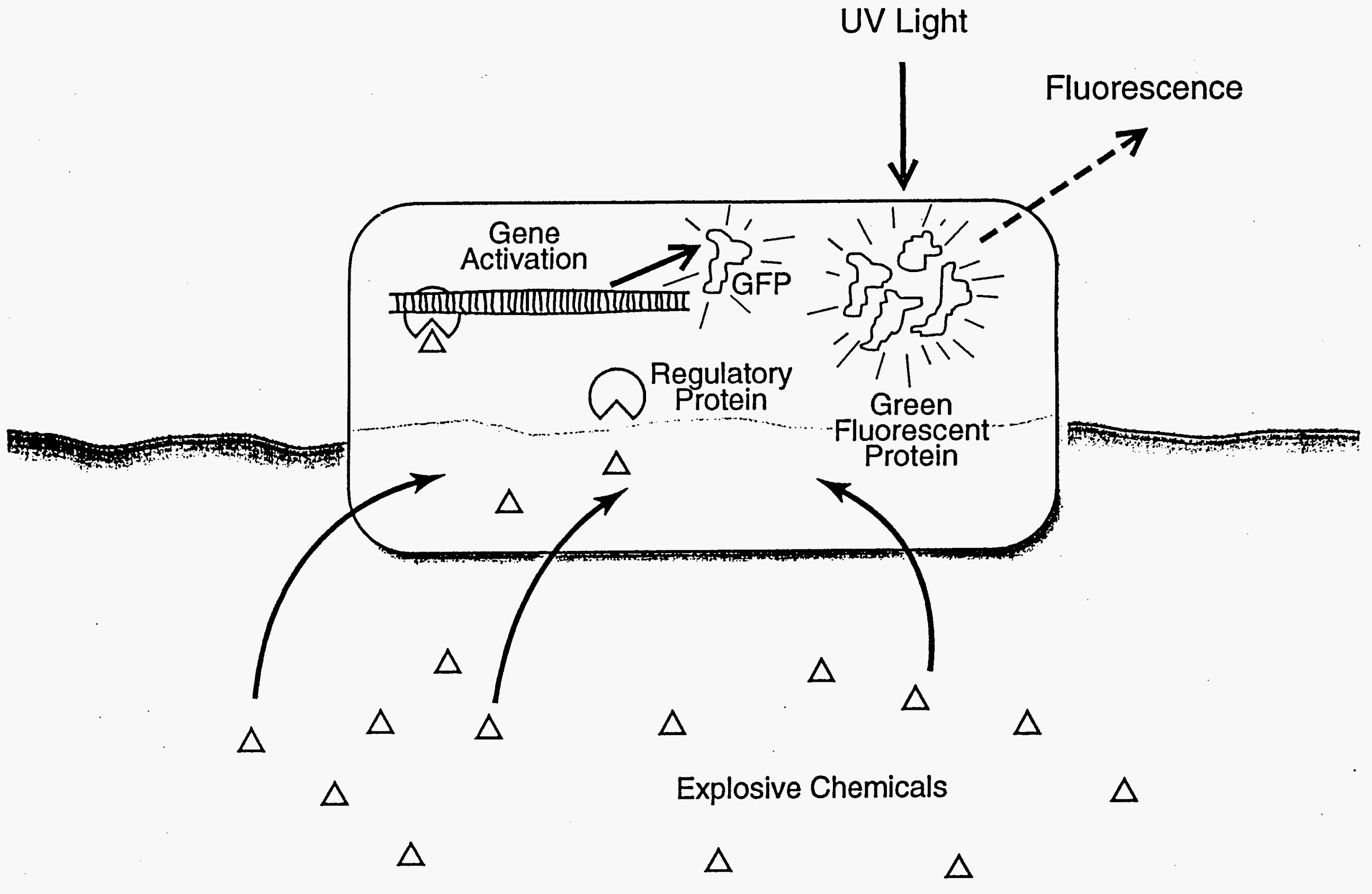




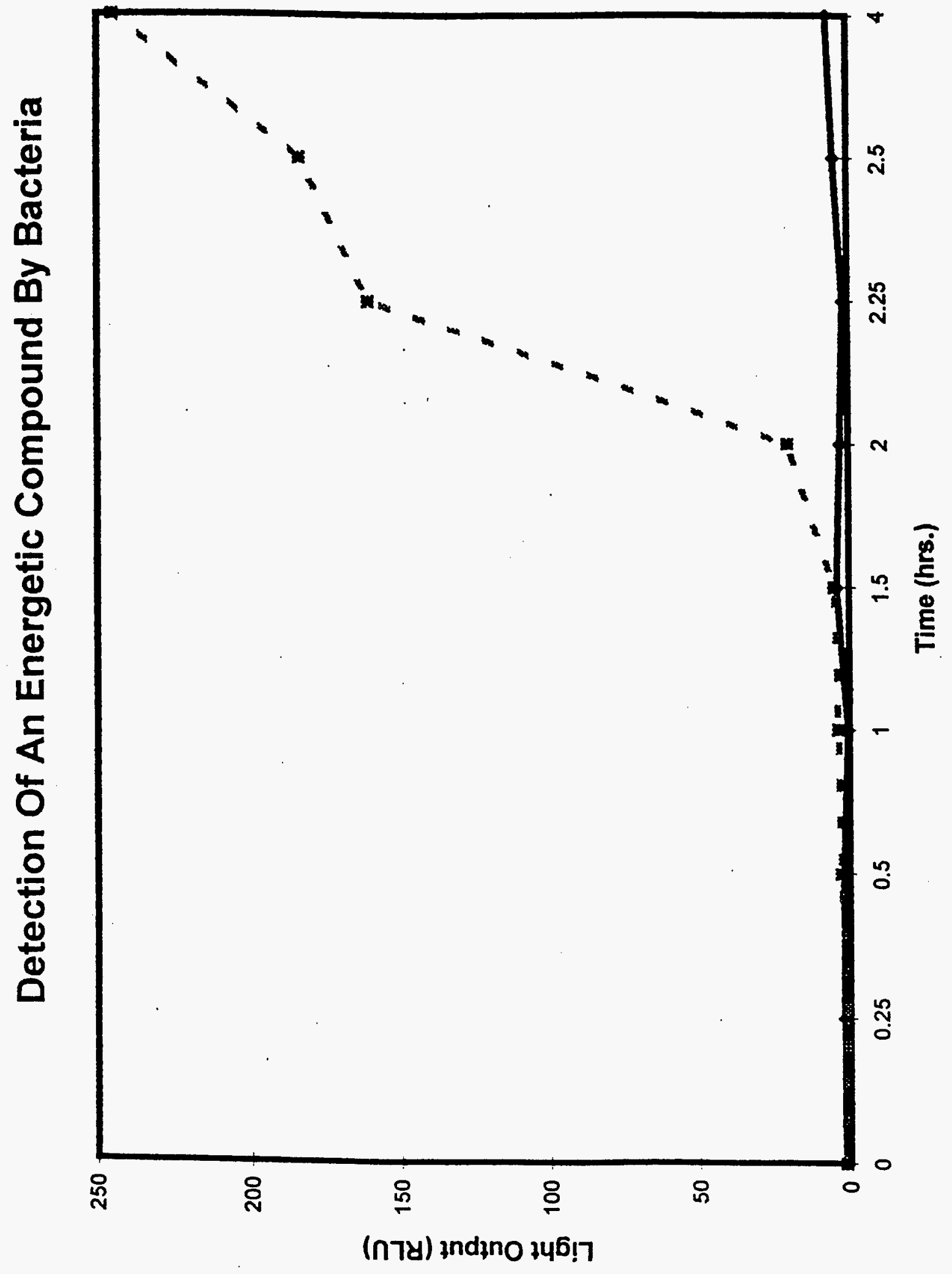



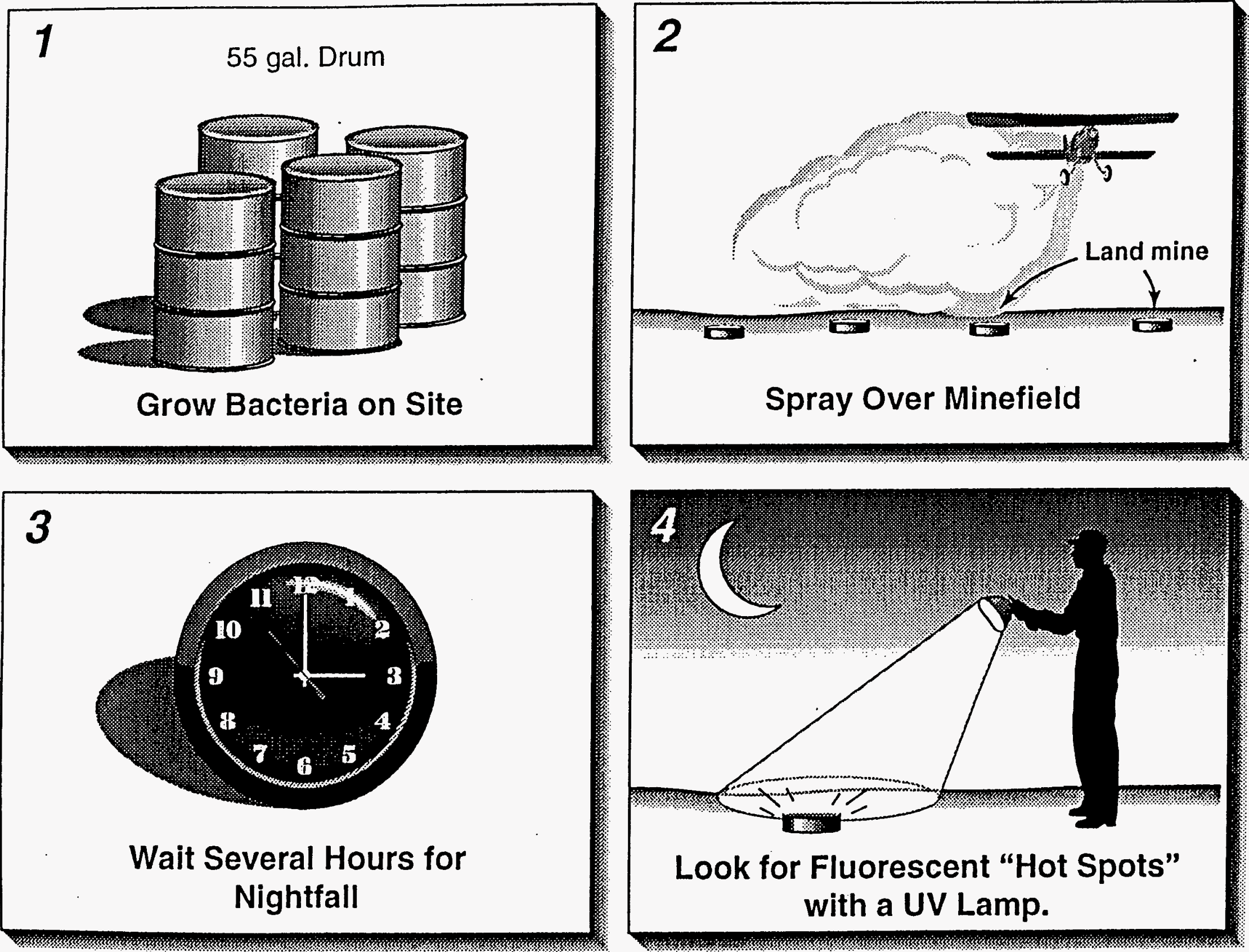
M98003374

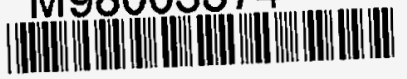

Report Number (14) $\frac{O R N L / C P-96972}{\text { CONF-980425- }}$

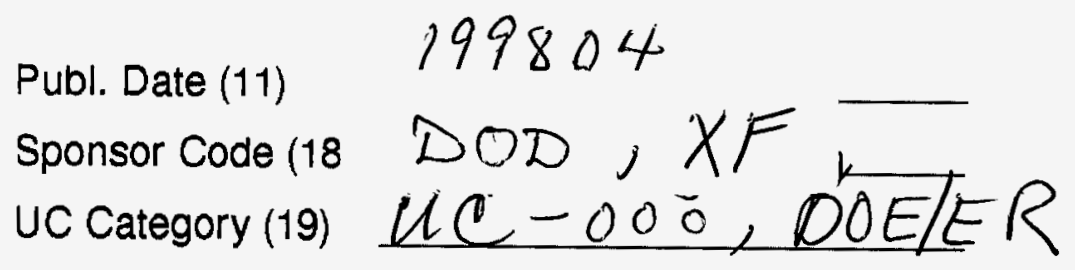

DOE 